\title{
Should bus commuting be subsidized for providing quality transport services? - A case for Delhi
}

\author{
AKSHAYA K SEN ${ }^{1}$, GEETAM TIWARI ${ }^{1}$ and V UPADHYAY ${ }^{1}$ \\ ${ }^{1}$ Transportation Research and Injury Prevention Programme, Indian Institute of \\ Technology, Hauz Khas, New Delhi 110016 \\ e-mail: geetamt@gmail.com
}

\begin{abstract}
Urban transport has serious problems that are symptoms of the general process of rapid urbanization and environmental degradation. Policymakers in general and urban economists in particular have paid little attention to public transport system pricing leading to the absence of a financially viable, self-supporting urban transport system.

In this paper, we report a partial equilibrium model developed by us, which captures transport tax reforms in the presence of certain transport externalities. Our theoretical model shows that the question of public transport subsidies to reduce congestion and provide quality transport services depends on three factors: (a) the extent to which such subsidies induce people to switch from private transport to public transport; (b) if the price elasticity of current users of public transport is higher, there may be a sharp rise in public transport ridership as a reaction to increased subsidies, which will have an undesirable effect; and (c) there is the danger that subsidies will cause a loss in productive efficiency.

The numerical model of our paper for Delhi shows that the cross price elasticity of public transport demand with respect to the price of private transport is significant $(0.63)$ in the off-peak period whereas the same in the peak period is somewhat low $(0 \cdot 16)$ and the combined effect of these elasticities will result in a considerable modal shift in favour of bus transport demand (19\%) if the price of public transport were to be subsidized and private transport were to be priced optimally. Even without subsidy, the modal shift will be significant (18\%), if the under-priced private transport modes are optimally priced keeping the current bus prices constant. This paper shows that there will be significant welfare gains in both these scenarios.
\end{abstract}

Keywords. Transport pricing; transport tax reforms; public transport subsidies; bus commuting; marginal external costs.

\section{Introduction}

With the rapid growth of urbanization in recent decades, public transport services, particularly bus services in many cities in India lack their full potential. Due to inefficient public transport systems, there has been an increase in the personalized mode of travel in most cities, leading 
to increase in traffic density resulting in longer travel time, reduced average speed, increased fuel consumption, higher levels of pollution and discomfort to road users.

The most important current problem in urban mass transit is the viability of mass transit as a financially self-supporting proposition (Anas 1982, 1985). Some of the few contributions to the computations of optimal transport pricing problem in a second best framework are reported in a few seminal papers (Glaister \& Lewis (1978); Small (1983); Ochelen \& Proost (1996); Proost \& Van Dender 2001). With respect to public transport pricing, some of the studies (Kraus 1989, 1991) conclude that a zero price for the urban bus service is justified in some cases (sufficient density of demand). A recent study (Ochelen et al 1998) suggests that subsidies for urban transit are justified (up to the point of zero prices, e.g., the London underground) when public funds are not expensive while the subsidy is transformed into a net tax in the case of costly taxation.

The present paper attempts to construct a strategic micro-economic partial equilibrium model, which captures transport tax reforms in different transport markets in the presence of transport externalities such as congestion, air pollution, accidents and noise. The principal contribution of the present model is the explicit computation of optimal private transport taxes with public transport subsidies through the use of an explicit welfare function that internalises these different types of externalities in a second best framework. With the model constructed in this paper, we address the following questions:

(i) How significant is the issue of efficient urban transport pricing with particular reference to bus pricing for providing quality transport services?

(ii) Should bus prices be subsidized in order to provide a quality public transport system?

(iii) How large is the modal shift in favour of bus transport through appropriate pricing interventions?

\section{An integrated approach to urban transport pricing and model}

Two major issues make the assessment of urban transport policies difficult: the presence of several types of transport externalities; and substitutability between alternative transport modes and vehicles. These two major difficulties necessitate a model where the idea is to look for the optimal combination of price and regulatory policies in the urban transport domain via the optimization of a welfare function subject to a set of constraints.

Figures $1 \mathrm{a}$ and $1 \mathrm{~b}$ serve the importance of interaction between different market segments by illustrating the relation between pricing of car and bus travel in peak times, assuming that for social or political reasons car use is under-priced.

The second-best theory argues that if prices are too low in one market, it is better to reduce prices below marginal social cost in the related market as well. And if the objective is to reduce the congestion caused by car transport, it is better to reduce the price of the alternative mode (bus travel) below the marginal social cost till the effective modal shift is achieved with, of course, increased social welfare. Let us assume that the price of a bus ticket is equal to the marginal resource cost (like fuel cost, maintenance costs, tyres, and vehicle depreciation) and bus traffic produces less external costs compared to car travel. This gives us equilibrium $E_{2}$ in figure $1 \mathrm{~b}$. Let us further suppose that it is not feasible to impose any extra tax on peak car traffic, which gives us equilibrium $E_{1}$ in figure 1 a where car users have to pay the resource cost and the average congestion cost, as is usually the case.

Here of course the volume of car traffic is far too high, because there remains a significant external cost - represented by the distance $\mathrm{AE}_{1}$ - for which car users are not charged. 


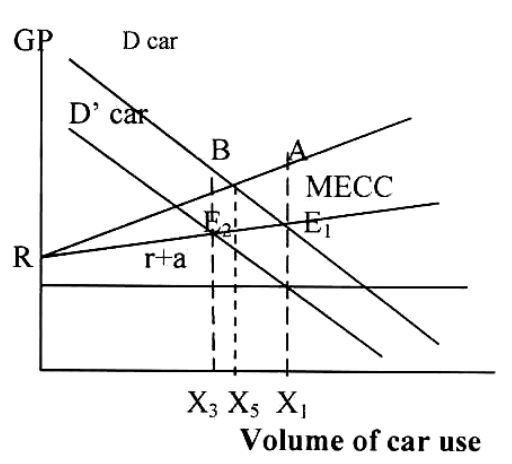

(a)

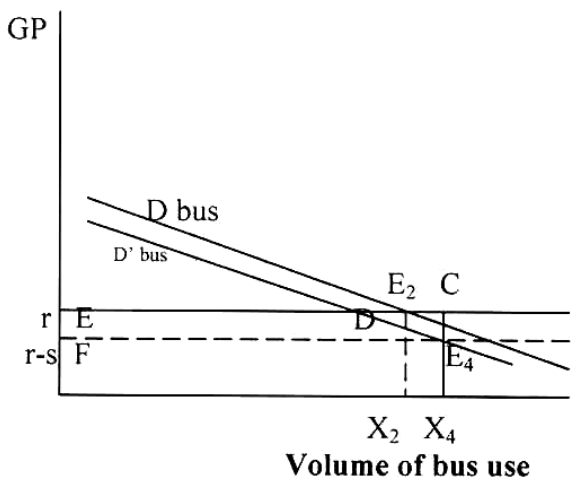

(b)

Figure 1. Pricing and interrelated transport markets: the example of pricing of car and bus travel in peak periods.

Assuming that peak traffic cannot be directly taxed, another approach would be to subsidize alternative modes of transport such as the bus. Assume also that the bus gets a subsidy $s$ which reduces the price of bus travel and consequently the demand for peak car travel shifts to the left (from $D$ to $D^{\prime}$ in figure 1a). The 'substitute mode' has become more attractive, and whatever the generalized price for car traffic there will be fewer cars on the road. This gives us a new peak period equilibrium $E_{3}$ at traffic volume $X_{3}$. The reduced traffic volume will cause an increase in the average speed and hence a fall in the generalized price for private car use, in turn causing a slight shift to the left in the demand for bus travel (from $D$ to $D^{\prime}$ in figure $1 b$ ). The final new equilibrium in the bus transport market is $E_{4}$ indicating a substantial modal shift in favour of the bus transport demand. Even with the feasibility of imposing an optimal tax on peak car use (at $E_{5}$ ), the subsidy to bus travel will cause an important modal shift towards bus transport $\left(X_{3}-X_{5}\right)$.

In the urban transport model one tries to find instruments like prices that bring the equilibrium from $A$ to $B$ in the complex interrelated transport markets with different modes, different sizes of vehicles, several types of fuels and several constraints on the use of the instruments. The model makes such interrelationships work via the prices that make transport users shift between different modes and types of vehicles, and via the time cost because the same network is shared by different transport modes.

The graph shows how a subsidy to public transport can cause a shift in demand in a related market. The graphs show that the subsidy will produce three other important welfare effects. First, there is the saving on external costs through the reduction in car traffic. These external cost reductions correspond graphically to the area $E_{3} B A E_{1}$. Second, there is an undesirable negative effect due to the 'excessive use' of buses in the sense that bus passengers pay less than the marginal cost of the journey. The efficiency cost, that is the difference between the marginal cost and the willingness to pay, corresponds to the area $E_{4} C D$. Third, there is an important transfer of income from the government to bus users. The total subsidy to the bus industry is $E C E_{4} F$ in figure $1 \mathrm{~b}$.

We can point to three factors, which need to be taken into account when deciding whether public transport subsidies constitute an effective instrument for dealing with peak-period congestion: (i) the extent to which such subsidies induce people to switch from private transport to public transport. If the price elasticity of car transport demand with respect to the price of 


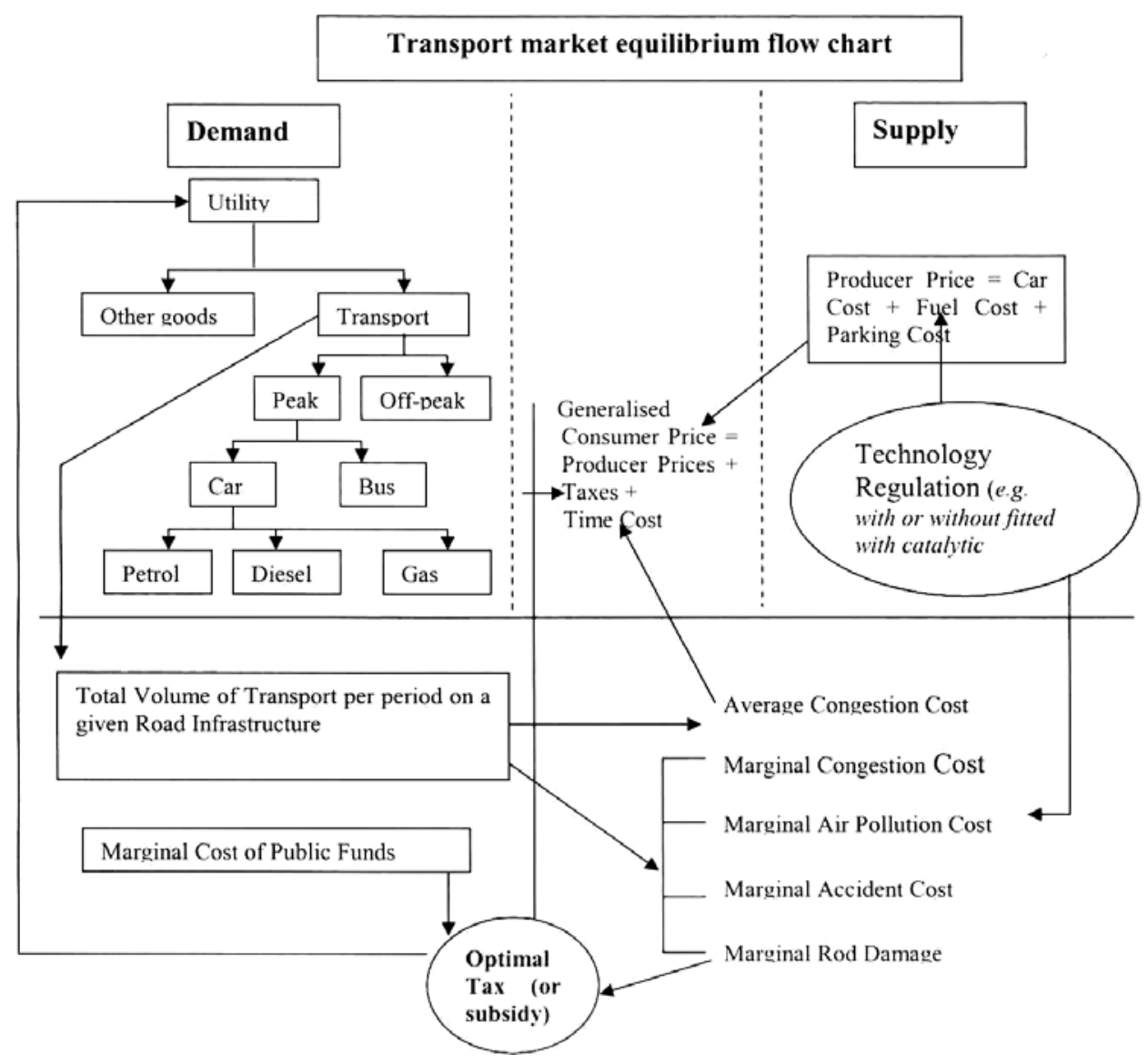

Figure 2. Transport market equilibrium flow chart.

bus transport is small, then subsidies would serve little purpose; (ii) if the price elasticity of current users of public transport is greater, there may be a sharp rise in public transport ridership as a reaction to increased subsidies, which will have an undesirable effect, namely, their extra use of public transport costs more than what they are willing to pay; (iii) there is the danger that subsidies will cause a loss in productive efficiency. If public transport companies can always rely on subsidies, there is a risk that, unknowingly, inefficiency will start creeping into the management and the workforce (so-called X-inefficiency).

The simplest structure used in our model is represented diagrammatically in figure 2 . The model represents the urban transport problem as a set of interrelated transport markets. The diagram contains three parts: demand, supply and an equilibrium price module.

A representative householder has different transportation options like: (i) he can vary his overall demand for transportation: choose between transport and other goods in maximizing his utility level; (ii) choose the moment of the day for his travel: peak or off-peak; (iii) choose between motorized and non-motorized transport; (iv) choose between transport modes (private or public) in order to fulfill his transportation needs; (v) choose between solo driving or shared driving (car pool); (vi) if the car mode is chosen, different sizes of vehicles are available; and (vii) lastly, he has to choose between several types of fuel: diesel or petrol or gas. This 
we call the 'demand part' of the model: it is the part where the choices or preferences of the consumers can be observed.

The 'supply part' of our model represents the activities and choices made by the producers of cars and the suppliers of other inputs like fuels, car maintenance, etc. Choices in the supply part of the model are made on the basis of maximum profit subject to government regulation on the technology and equipment of vehicles.

In the equilibrium price module, generalized prices consisting of producer prices, transportation time costs and taxes or subsidies are computed for different types of transportation modes.

\subsection{Mathematical formulation}

The consumer's preferences are represented in the following utility function:

$$
\operatorname{Max} . U=u\left(x_{0}, x_{1}\right) \quad(\mathrm{i}=1, \ldots \ldots, \mathrm{I}),
$$

subject to:

$$
\begin{aligned}
& Y=q_{0} x_{0}+\sum_{i} q_{i} x_{i}=q_{0} x_{0}+\sum_{i}\left(q_{i}+\rho_{i} t_{i}\right) x_{i} \\
& \Rightarrow \bar{y}+\mathrm{PS}+\mathrm{TAXREV}=q_{0} x_{0}+\sum_{i}\left(q_{i}+\rho_{i} t_{i}\right) x_{i},
\end{aligned}
$$

where $x_{0}=$ composite (non-transport) commodity with price normalized at one, $x_{1}=$ transport goods, and $Y=$ total income of the consumer. The budget constraint states that spending on transport which is based on the generalized price of the transport $\left(q_{i}+\rho_{i} t_{i}\right)$ and other goods should be equal to the total income $(Y)$ which is the sum of his labour income $(\bar{y})$, profits out of producer's surplus (PS) and the government transfer (TAXREV). The consumer's problem of efficiently allocating his money and time resources may be expressed as the maximization of the following Lagrange function:

$$
\Im=u\left(x_{0}, x_{1}\right)+\lambda\left[\bar{y}+\mathrm{PS}+\mathrm{TAXREV}-q_{0} x_{0}-\sum_{i}\left(q_{i}+\rho_{i} t_{i}\right) x_{i}\right],
$$

where the Lagrange multiplier, $\lambda>0$ represent shadow variables for marginal utility of money income. The optimization process yields the following first order conditions (FOC):

$$
\begin{aligned}
& \partial \Im / \partial x_{0}=u_{0}-\lambda q_{0}=0 \Rightarrow u_{0}=\lambda q_{0}, \\
& \partial \Im / \partial x_{i}=u_{i}-\lambda, \\
& \sum_{i}\left(q_{i}+\rho_{i} t_{i}\right)=0 \Rightarrow u_{i}=\lambda \sum_{i}\left(q_{i}+\rho_{i} t_{i}\right), \\
& \partial \Im / \partial \lambda=\bar{y}+\mathrm{PS}+\mathrm{TAXREV}-q_{0} x_{0}-\sum_{i}\left(q_{i}+\rho_{i} t_{i}\right) x_{i}=0 \\
& \left.\Rightarrow \bar{y}+\mathrm{PS}+\mathrm{TAXREV}=q_{0} x_{0}+\sum_{i}\left(q_{i}+\rho_{i} t_{i}\right) x_{i} \text { (B.C. }\right) .
\end{aligned}
$$


The consumer optimization problem (1) implies that the FOC (4) for the above generalized budget constraint (2) must hold at given prices, taxes and exogenous congestion levels.

The demand for transport is described by an indirect utility function that contains the tradeoff between spending income on non-transport goods and a range of transport goods. The first order conditions of system (4) enable us to write the indirect utility function $V$ of a consumer as a function of the vector of generalized prices and generalized income as follows:

$$
V=v\left[q_{0},\left(q_{i}+\rho_{i} t_{i}\right), \bar{y}+\mathrm{PS}+\mathrm{TAXREV}\right],
$$

In order to find the monetary welfare measure for the above indirect utility function, it can be divided by the marginal utility of income in the reference equilibrium $\left(\mu_{r}\right)$. Different transport markets are considered, including peak vs off-peak, private vs public vehicles and so on. The indirect utility function of type (5) gives the government welfare maximization function with $N$ identical consumers.

We assume that there are $i=1, \ldots, I$ different passenger transport demand categories (use of bus, small car, large car, etc.) that can each be satisfied by $j=1, \ldots, J$ supply technologies (e.g. for $i=$ small car we could have small car with catalytic converter $(j=1)$, small car without catalytic converter $(j=2)$, etc.). Individual demand for a certain type $i$ of transportation equals $x_{i}$ and is satisfied by a total supply of $J$ different car technologies $Z_{i j}$. There are $N$ identical consumers.

Our model is a partial equilibrium approach in the sense that the feedbacks on other markets are neglected. For simplicity, we abstract from the freight transport market.

The government's problem, then, is to maximize the aggregate consumers welfare (given by the indirect utility function (5)), subject to two constraints as given below:

$$
\begin{aligned}
\operatorname{Max} & \frac{N}{\mu_{r}} \mathrm{~V}\left[q_{o}, q_{i}+\rho_{i} t_{i} ;(i=1 \ldots \ldots), Y\right. \\
+ & \left.\frac{1}{N} \sum_{l, i}\left(p_{l}-r c_{l i}\right) z_{l i}+\sum_{i}\left(q_{i}-p_{i}\right) x_{i}\right] \\
& +\lambda \sum_{i}\left(q_{i}-p_{i}\right) N x_{I}-\sum_{l, i}\left(e c_{l i} z_{l i}\right)
\end{aligned}
$$

subject to the following constraints

$$
\begin{aligned}
& \sum_{i} z_{i j} \geq N x_{i} \forall i=1, \ldots \ldots, I \\
& p_{l} \geq r c_{l j} \forall l=1, \ldots, I ; \forall j=1, \ldots, J .
\end{aligned}
$$

The first term in (6) measures the utility as a function of generalized prices, income $(Y)$, profits ( $z_{i j}$ is the supply of vehicle $\mathrm{km}$ of mode $i$ and technology $j$ ) and transferred tax revenue, divided by the marginal utility of income $\left[\mu_{r}\right]$ in a reference situation. Prices of non-transport goods, $q_{0}$, are assumed to remain fixed. The second term of (6) measures the extra shadow value of public funds $(\lambda)$. The third term measures the total revenue loss due to subsidy given to the public transport. The last term measures the total environmental damage in income equivalents.

The objective function is maximized with respect to $p_{i}, q_{i}$ and $z_{i j}$, subject to the two constraints given in (7). In addition, we require that all variables take positive values. The first 
constraint states that demand has to be satisfied by the sum of the technologies supplied (the supply of transport has to be corrected for the occupancy rate in order to match the demand of passenger $\mathrm{km}$ ). The second constraint states that producer prices should be larger than or equal to the marginal resource costs. This can be justified by compatibility constraints for the producers. Subsidies for public transport are here represented by a producer price that is larger than the consumer price.

We use Lagrange multipliers $\alpha i$ for the first constraint and $\gamma i j$ for the second constraint. We look for an optimum with respect to the control variables $q_{i}$, and $z_{i j}$. This implies that the demand level $x$ is controlled indirectly via the consumer prices $q$ so that all optima of the model are by construction always consumer optima. Taxes on consumers are implicitly determined via the difference between $q$ and $p$. The optimum will satisfy the complementary slackness conditions associated to (4), (5) and (6) as well as the following first order Kuhn Tucker conditions for an interior optimum $\left(x_{k q i}\right.$ represents the derivative of xk with respect to the consumer price of good $i$ ).

$$
\begin{aligned}
& \mu \frac{N}{\mu_{r}} x_{i}-\mu \frac{N}{\mu_{r}} \sum_{l \in S_{i}} \rho_{l} x_{l} t_{l q i}+\mu \frac{N}{\mu_{r}} x_{i}+\mu \frac{N}{\mu_{r}} x_{i} \sum_{k}\left(q_{k}-p_{k}\right) x_{k q i}+\lambda N x_{i} \\
& \quad+\lambda \sum_{k}\left(q_{k}-p_{k}\right) N x_{k q i}+\sum_{k} \alpha_{k} N x_{k q i}=0, \\
& N \frac{\mu}{\mu_{r}}\left(\sum_{j} z_{i j}-x_{i}\right)-\lambda N x_{i}-\gamma_{i j}=0, \\
& \left(p_{i}-\mathrm{rc}_{i j}\right)-\mathrm{ec}_{i j}-\alpha_{i}=0 .
\end{aligned}
$$

\subsection{Market equilibrium and optimal tax rules}

The above solution corresponds to a market equilibrium where the government regulates the supply technologies to be used, where producers maximize profits, taking prices as given. The consumers select their preferred consumption bundle given the consumer prices and where the government combines regulation and consumer taxes to maximize overall welfare. In the optimum only resource costs (rc) and external costs (ec) determine which technologies should be used, i.e.

$$
\mathrm{rc}_{k l}+\mathrm{ec}_{k l}=\mathrm{rc}_{k n}+\mathrm{ec}_{k n}
$$

Producer prices equal the lowest marginal resource costs of the set of technologies that are allowed by the policymaker. This corresponds to the outcome of a perfectly competitive market with regulations on the type of transport technologies that can be used.

The first order conditions given in (8) to (10) can be expressed in the form of uncompensated price elasticities $(\varepsilon)$ with respect to own prices (own price elasticities) and with respect to alternative modes (cross-price elasticities) as shown in the system of equations (12). The price elasticities show the change in congestion level via change in the demand for transport goods caused by their price changes. Using (7(i)) and (8) we obtain the following expression for 
optimal tax on passenger transport $\left(\tau_{k}\right)$ :

$$
\begin{gathered}
{\left[\tau_{k}-\frac{\operatorname{tmcong}_{k}+\mu_{r} / \mu e c_{k}}{\left(1+\lambda \mu_{r} / \mu\right)}\right] \frac{\varepsilon_{k k}}{q_{k}}=\frac{\lambda \mu_{r} / \mu}{\left(1+\lambda \mu_{r} / \mu\right)}} \\
\frac{\tau_{k}}{q_{k}}=\left[\frac{\lambda \mu_{r} / \mu}{\left(1+\lambda \mu_{r} / \mu\right)}\right] \cdot \frac{1}{\varepsilon_{k k}}+\frac{1}{q_{k}} \cdot\left[\frac{\operatorname{tmcong}_{k}+\mu_{r} / \mu e c_{k}}{\left(1+\lambda \mu_{r} / \mu\right)}\right] . \\
\text { 业 }
\end{gathered}
$$

\section{Ramsey component Pigouvian component}

Where tmcong $g_{k}$ is the total marginal congestion cost of increasing the use of passenger transport mode $k(\mathrm{mk})$ :

$$
\operatorname{tmcong}_{k}=m_{k}\left[N \sum_{i \in S_{k}} \rho_{i} x_{i} T_{i i}\right] .
$$

As can be seen from (12), transport taxes $\tau_{k}$ contain two similar components: the first term being the Ramsey component and the second term being the Pigouvian component.

The external congestion cost of an increase of passenger transport of type $k$ is defined in (13) and consists of the value of the time losses for all transport users. In (12), taxes become Pigouvian taxes when $\lambda=0$. When $\lambda$ increases, the externality part of the optimal tax decreases below the pure Pigouvian component and the Ramsey component increases.

Now, we consider the cross price effects between the different passenger transport goods studied where we have to consider the existing price distortions for complements and substitutes. A typical expression considering the cross-price effects between bus and car use can be given as follows:

$$
\begin{aligned}
\frac{\tau_{1}}{q_{1}}= & {\left[\frac{1+\lambda \mu_{r} / \mu}{\lambda^{\mu_{r} / \mu}}\right] \frac{1}{\varepsilon_{11}}-\frac{1}{q_{1}}\left[\frac{\varepsilon_{21}}{\varepsilon_{11}} \cdot \frac{x_{2}}{x_{1}}\left(\tau_{2}-\mathrm{mec}\right)\right]+\frac{1}{q_{1}} \mathrm{mec}, }
\end{aligned}
$$

\section{Ramsey comp. Trip interaction component Pigouvian comp.}

where mec is marginal external costs and subscripts 1 and 2 represent car and bus transport respectively. The second term is called 'trip interaction component' which shows the deviation between taxes and marginal external costs on the other transport markets. It explains the interactions between taxes in the presence of price distortions on other transport markets. For example, if there are large distortions in the peak car market, then subsidizing the peak bus transport market will reduce the distortions in the peak car market.

\section{A numerical illustration for Delhi}

\subsection{Model structure and components}

The theoretical model is calibrated (using GAMS software program) using present taxes and prices, quantities and regulations for all transport modes together with information on the 
Table 1. Elasticities of substitution and compensated own- and cross- price elasticities, optimal equilibrium.

\begin{tabular}{|c|c|c|}
\hline Elasticities of substitution & Found in literature & Computed in reference scenario \\
\hline Transport - other commodities & $0 \cdot 6$ & $0 \cdot 6$ \\
\hline peak - off peak transport & $0 \cdot 8$ & 0.8 \\
\hline big - small cars & 1.5 & 1.5 \\
\hline Petrol-diesel & 1.5 & 1.5 \\
\hline \multicolumn{3}{|c|}{ Compensated own - price elasticities } \\
\hline Peak car transport & $-0 \cdot 30$ & -0.55 \\
\hline Off peak car transport & -0.60 & -0.85 \\
\hline Peak bus transport & -0.35 & $-0 \cdot 18$ \\
\hline Off peak bus transport & -0.87 & -0.66 \\
\hline \multicolumn{3}{|c|}{ Compensated cross - price elasticities } \\
\hline Car peak - car off-peak & 0.05 & 0.04 \\
\hline Car peak - bus peak & 0.71 & $0 \cdot 16$ \\
\hline Car off-peak-bus off-peak & 0.58 & 0.63 \\
\hline Bus peak-car peak & 0.03 & 0.02 \\
\hline Bus peak-bus off-peak & 0.04 & 0.004 \\
\hline Bus off-peak-car off-peak & 0.02 & $0 \cdot 16$ \\
\hline
\end{tabular}

Source: De Borger, et al (1996), Proost \& Van Dender, 2001

case of substitution between transport and other goods as well as between different means of transport. This generates a reference solution. The reference solution can be compared with the 'best' second best solution where all goods and externalities can be priced perfectly. The demand function is structured through constant elasticity of substitution (CES) nested utility function (the CES is a particular practical functional form which has the property of a 'constant elasticity of substitution': the relative degree of substitution between two goods in response to a price change is constant) (Keller 1976). In this model 20 final transport goods and one non-transport good are represented. The total demand on each of the 20 transport markets is a function of the generalized prices (money plus time costs) of all transport modes and of generalized income. This is implemented by formulating each nest as a CES: the good ' $x_{1}$ ' is defined as a CES subutility function with, as arguments, the goods 'peak' and 'off peak', the good 'peak' is then itself a CES subutility function of non-motorized and motorized, etc.

Table 1 gives price elasticities for our model computed in the reference equilibrium, which also conform to estimates available from literature (De Borger et al 1996; Proost \& Van Dender 2001).

The vehicle supply categories taken for this study are public transport vehicles represented by buses; and cars represent private transport modes. Buses are assumed to use the same road network as cars and contribute to the overall road congestion in the same way. The public transport mode is both characterized by external costs (of air pollution, accidents and noise) and resource costs. On the private transport side we distinguish six different inputs, which combined to produce a car kilometer. There is no substitution possible between these inputs, their proportions are thus fixed. To obtain one $\mathrm{km}$ in period $X$ by individual of type $Y$ with car type $Z$, there is a fixed amount of fuel and parking time needed, the other costs are vehicle depreciation costs, insurance costs, maintenance costs and (in case of) road toll costs. 
We use a constant cost for each vehicle type (this means a differentiation by size and fuel type). The relevant costs are the marginal costs per vehicle $\mathrm{km}$. All major external effects are taken into account: congestion, air pollution, noise and accidents. These external costs are calculated separately and used in the model.

\subsection{Transport markets and traffic flows in Delhi}

The geographical area for this case study is the entire Delhi Urban Agglomeration (DUA) with a population of 12.90 million (Registrar General and Census Commissioner, India 2001). The bus system in Delhi is a mix of public and private buses. At present the regular bus system comprises of 4000 private buses and 3760 Delhi Transport Corporation (DTC) buses including 1000 private buses under administrative control of DTC. About 5000 chartered buses provide point-to-point service during peak hours supplementing these regular bus services. The bus transport system is the backbone of transport system in Delhi. However, it is plagued with numerous problems that have crept in to the system over the years.

Data on traffic flows are derived from the estimates and projections made in various reports like ORG (1994), RITES (2005) and I-CE (2001). The flows are measured for a representative day. All prices, costs and taxes are for 2005, assuming that there is no change in policy since 2001. According to existing studies, the share of private car transport in total traffic flow is approximately $28 \%$ whereas the share for bus transport in total traffic flow is $36 \%$. The remaining $35 \%$ is shared by motorized 2-wheelers (29\%), auto-rickshaws (2\%), bicycles $(3 \%)$ and walk trips $(2 \%)$.

The average speed of a car in peak hours is $24 \mathrm{~km} / \mathrm{h}$ while for bus transport it is $21 \mathrm{~km} / \mathrm{h}$. Only passenger transport flows have been modelled. On an average, the per capita trip rate per day in DUA is 0.7816 without walk trips and 1.139 with walk trips. The average length of a car trip is estimated as $14.58 \mathrm{~km}$ whereas it is $16.99 \mathrm{~km}$ for a bus trip. Non-motorized transport has average distances of approximately $5.66 \mathrm{~km}$ whereas average walk distance is approximately $0.83 \mathrm{~km}$. Daily traffic flows in Delhi are spread unequally overtime. For analytical and conceptual reasons, only two time intervals are considered in the model. The off-peak period stretches over 15 hours $(0400-800 \mathrm{hrs}, 1000-1700 \mathrm{hrs}$ and $2000-0000 \mathrm{hrs})$, the peak period contains the morning and evening peaks (0800-1000 hrs and 1700-2000 hrs) totalling 5 hours. The period from 0000 midnight to $0400 \mathrm{hrs}$ is not taken up in the analysis. According to our estimation, 55\% of all trips are made during the peak hours.

The model gives major inefficiencies in the present pricing system and computes the effects of policies in the so-called 'counter-factual equilibria' (the reference situation may be called the 'factual equilibrium'). The following four counter-factual equilibria are presented (these counter-factual equilibria are computed without regulation on vehicle technology and without parking charges):

(i) Subsidy-based pricing (SP): This policy subsidizes bus transport prices (by 25\%) to correct inefficiencies in the private transport markets assuming that extra tax cannot be imposed in the private transport market and the present pricing in the private transport market is to continue.

(ii) subsidized optimum (SO): This policy sets optimum private transport prices to correct inefficiencies in the transport markets while public transport prices are subsidized by $25 \%$ in order to have a significant modal shift.

(iii) Partial optimum (PO): This policy sets optimum private transport prices to correct inefficiencies in transport markets while public transport prices are kept the same as at the reference level and not optimized. 
(iv) Full optimum (FO): This policy sets policy instruments perfectly to alleviate the existing inefficiencies in transport market. Both public and private transport prices are optimized. The optimal taxes consider all differences in external costs of the reference situation.

\subsection{Model calibration and reference equilibrium-2005}

Calibration requires that the entire model specification be capable of generating a (benchmark) equilibrium observation as a model solution. For our case study, a congestion function has been derived through a speed-flow relationship function, with a car free flow speed of $45 \mathrm{~km} / \mathrm{h}$, peak traffic speed of $24 \mathrm{~km} / \mathrm{h}$ and off-peak traffic speed of $40 \mathrm{~km} / \mathrm{h}$.

The reference situation is described in table 2. The upper part of table 2 presents the cost structure for a number of transport markets in Delhi in 2005. The first row shows the price per passenger kilometer ( $\mathrm{pkm}$ ) of a small petrol car driven alone during the peak hours. We note:

Table 2. Characteristics of the reference situation (Delhi, 2005).

\begin{tabular}{|c|c|c|c|c|c|}
\hline $\begin{array}{l}\text { Prices and costs } \\
(\mathrm{Rs} / \mathrm{pkm})\end{array}$ & $\begin{array}{l}\text { Resource } \\
\text { cost }\end{array}$ & $\operatorname{tax}$ & $\begin{array}{l}\text { Money } \\
\text { price }\end{array}$ & $\begin{array}{l}\text { Marginal } \\
\text { ext. cost } \\
\text { (per vkm) }\end{array}$ & $\begin{array}{c}\text { generalized } \\
\text { price }\end{array}$ \\
\hline \multicolumn{6}{|l|}{ Peak } \\
\hline car,solo,small,petrol & $4 \cdot 84$ & 1.57 & $6 \cdot 41$ & $7 \cdot 00$ & 8.70 \\
\hline car,solo,small,diesel & $3 \cdot 45$ & 0.53 & 3.97 & $8 \cdot 38$ & $6 \cdot 26$ \\
\hline car,solo,big,petrol & $7 \cdot 57$ & $2 \cdot 04$ & $9 \cdot 61$ & $7 \cdot 11$ & 11.91 \\
\hline car,solo,big,diesel & 5.49 & 0.65 & $6 \cdot 14$ & 9.42 & 8.43 \\
\hline Public Transport (BUS) & $0 \cdot 37$ & 0.03 & $0 \cdot 39$ & $11 \cdot 17$ & $2 \cdot 08$ \\
\hline \multicolumn{6}{|l|}{ Off-peak } \\
\hline car,solo,small,petrol & $4 \cdot 66$ & $1 \cdot 36$ & $6 \cdot 02$ & $2 \cdot 39$ & $7 \cdot 15$ \\
\hline car,solo,small,diesel & $3 \cdot 32$ & 0.46 & 3.79 & $3 \cdot 18$ & 4.91 \\
\hline car,solo,big,petrol & $7 \cdot 28$ & 1.70 & 8.98 & 2.46 & $10 \cdot 11$ \\
\hline car,solo,big,diesel & $5 \cdot 13$ & 0.56 & $5 \cdot 87$ & 3.75 & $7 \cdot 00$ \\
\hline Public Transport (BUS) & 0.77 & 0.04 & 0.82 & $2 \cdot 25$ & 1.95 \\
\hline \multicolumn{6}{|l|}{ Volume \& Composition of Traffic } \\
\hline & Million/km & $\begin{array}{l}\text { Share } \\
(\%)\end{array}$ & $\begin{array}{c}\underset{(\%)}{\text { carpool }} \\
\text { (\%) }\end{array}$ & $\begin{array}{l}\text { Speed } \\
(\mathrm{km} / \mathrm{h})\end{array}$ & $\begin{array}{c}\text { PCU } \\
\text { (mil/day) }\end{array}$ \\
\hline Peak, private & $15 \cdot 22$ & $22 \cdot 07$ & $19 \cdot 02$ & $24 \cdot 00$ & \\
\hline Peak, public & $22 \cdot 71$ & 32.94 & & $21 \cdot 37$ & \\
\hline Total peak & 37.93 & 55.01 & & & 2.85 \\
\hline Off-peak, private & $12 \cdot 44$ & $18 \cdot 04$ & $18 \cdot 92$ & $40 \cdot 00$ & \\
\hline Off-peak, public & $18 \cdot 59$ & $26 \cdot 95$ & & $35 \cdot 62$ & \\
\hline Total off-peak & 31.02 & 44.99 & & & $0 \cdot 83$ \\
\hline Total volume & $68 \cdot 95$ & $100 \cdot 00$ & & & $3 \cdot 67$ \\
\hline \multicolumn{6}{|l|}{ Tax revenue (million Rs/day) } \\
\hline Private & $30 \cdot 25$ & & & & \\
\hline Public & 2.72 & & & & \\
\hline $\begin{array}{l}\text { External costs other than } \\
\text { congestion (million Rs/day) }\end{array}$ & $72 \cdot 04$ & & & & \\
\hline Welfare level & $1750 \cdot 94$ & & & & \\
\hline
\end{tabular}

Note: car, solo, small, petrol indicate: small petrol car driven alone 
(i) The time cost (Rs 2.3/vehicle $\mathrm{km}$ ), which is the difference between generalized price and money price, equals $26 \%$ of the total trip cost. In the off-peak, for an otherwise identical trip, this share is only $15 \%$.

(ii) The cost of a kilometre by diesel car is lower than the cost for a petrol car. This is due to lower taxes on diesel vehicles and the lower resource costs pkm of diesel vehicles (due to higher average mileage). The tax system has to be reformed such as to increase the total tax on diesel cars (by increasing the tax on the fixed costs of diesel cars).

(iii) Taxes are far below marginal external costs in the peak period, while the same is somewhat better in the off-peak period where the marginal external cost is very less. This suggests that the present tax structure is badly suited for the internalization of external costs. Marginal external costs are much higher in peak hours than in off-peak hours due to the higher marginal external costs of congestion which are very high during peak hours.

(iv) As for public transport, it is noted that the money price in off-peak is higher than that in the peak period. This is due to strong discrepancy of resource costs on a pkm basis in both periods, which is due to differences in occupancy rates. The same bus is used in peak and off-peak periods but during peak hours there is an average of 66 persons on board, as opposed to 30 passengers on average during off-peak periods. As a consequence, peak and off-peak bus driving covers more than the marginal resource costs of the bus. For public transport, the share of time costs in the total travel costs is higher than for private transport (81\% in peak and $58 \%$ in off-peak hours to be precise). The reason is that walking times to and at bus stops are included in the travel time.

In table 2 the level and composition of traffic have been summarized. Peak period traffic accounts for $55 \%$ of the total traffic, expressed in passenger kilometres. Public transport stands for $60 \%$ of all pkm (33\% in peak and $27 \%$ in off-peak). Within the peak period, $60 \%$ of all pkms is produced by public transport. Even the off-peak period, this share is $60 \%$. This explains the fact that the use of public transport mode in Delhi is more frequent. The average share of car-pooling in the total number of passenger kilometre is approximately $19 \%$ in both periods. Given the expected traffic volumes, average speeds are expected to be about 24 $\mathrm{km} / \mathrm{h}$ for passenger car during peak hours and about $40 \mathrm{~km} / \mathrm{h}$ during off-peak hours. Public transport travels slower than private transport.

Table 2 shows that aggregate tax revenue from both private and public transport is positive. The total value of the external costs of pollution, accidents and noise is Rs 72.04 million per day.

Driving in Delhi at an average trip length of $14.58 \mathrm{~km}$ in peak period in a small petrol car will cost about Rs 127/- per trip. This price is generalized which decomposes into a time cost of Rs 33.50 and a money cost of Rs 93.50. The cost of the same trip during off-peak periods is Rs 104/- consisting of time cost of Rs 16/- and money cost of Rs 88/-. The situation described here is inefficient because of two reasons directly related to transport sector: (i) the resource cost of parking is not charged to the drivers, which results in inefficiently high demand for transport; (ii) prices are below social costs, which means external costs, particularly high in the peak period, is not internalized. Social costs are the total costs of a trip to society. Apart from resource costs, they include marginal external costs. Total marginal external costs (of congestion, pollution, accidents and noise) per passenger $\mathrm{km}$ for a small petrol driven car comes to around Rs 7.00 in the peak hours and Rs 2.39 in the off-peak hours which amounts to Rs 102/- per trip in the peak and Rs 35/- in the off-peak period. The discrepancy between prices and social costs leads to an inefficiently high demand for transport. 


\subsection{Model optimization and optimal policy}

In the optimal policy, prices are set such that they reflect marginal external costs as far as possible in all transport markets. Since resource costs are fixed per kilometer, taxes and subsidies are used to achieve these optimal prices. Here, we consider four optimal policies: (i) where public transport prices are subsidized on the assumption that the current inefficient private transport prices cannot be changed due to social and political reasons (we call it 'subsidy-based pricing', SP); (ii) where only private transport prices are optimized and public transport prices are subsidized by $25 \%$ in order to induce a modal shift (we call it 'subsidized optimum', SO) to reduce congestion; (iii) where only private transport prices are optimized and public transport prices are fixed at the reference level (we call it 'partial optimum', PO); and (iv) the full optimum (FO) where both the private and public transport prices are optimized. In the optimal policy, there is (nearly) no restriction on the flexibility of taxes: they may differ according to time of day, type of vehicle, fuel etc. It is clear that implementation of such a pricing policy will require a highly sophisticated tolling mechanism such as electronic road pricing. Even with this electronic road pricing the question remains whether they will allow variable emission taxes and hence implementation of full optimum pricing is difficult given the present set-up.

3.4a Welfare changes and volume effects: Our principal standard of policy assessment is welfare. It is a monetary measure of the net benefits of a given economic equilibrium. It takes account of the benefits accruing to all consumers and producers, on the assumption that tax revenues are used by the government to improve consumer welfare. The impact of negative externalities is accounted for by subtracting the monetary value of these impacts from welfare. Tables 3 and 4 summarize the results of the optimal pricing policy. The four counterfactual equilibria are compared with the reference scenario (RF).

Since the principal standard for policy assessment is the overall welfare level we can clearly see from the above tables that the introduction of full optimal pricing with respect to external costs leads to a welfare gain of $3.23 \%$ of generalized income, as compared to the reference situation. Though full optimum pricing is the best pricing scenario, it may not

Table 3. Key results of optimal policy (Delhi, 2005).

\begin{tabular}{|c|c|c|c|c|c|}
\hline & \multicolumn{5}{|c|}{ Equilibrium conditions } \\
\hline & $\mathrm{RF}$ & SP & SO & $\mathrm{PO}$ & FO \\
\hline Welfare level & $1750 \cdot 94$ & $1745 \cdot 61$ & $1756 \cdot 96$ & 1765.68 & 1807.48 \\
\hline$\%$ Welfare gain & $0 \cdot 00$ & $-0 \cdot 30$ & $0 \cdot 34$ & 0.84 & $3 \cdot 23$ \\
\hline$\%$ Maximal welfare gain & 0.00 & -9.29 & $10 \cdot 53$ & $26 \cdot 01$ & $100 \cdot 00$ \\
\hline Traffic level (Million pkm) & $68 \cdot 95$ & $72 \cdot 15$ & $76 \cdot 87$ & $73 \cdot 86$ & $48 \cdot 41$ \\
\hline$\%$ Peak traffic & $55 \cdot 00$ & $52 \cdot 38$ & $52 \cdot 52$ & $53 \cdot 88$ & $50 \cdot 28$ \\
\hline$\%$ Off-peak traffic & $45 \cdot 00$ & $47 \cdot 62$ & $47 \cdot 48$ & $46 \cdot 12$ & $49 \cdot 72$ \\
\hline$\%$ Private traffic & $40 \cdot 11$ & $35 \cdot 70$ & 29.04 & $29 \cdot 20$ & $35 \cdot 63$ \\
\hline$\%$ Public traffic & $59 \cdot 89$ & $64 \cdot 30$ & $70 \cdot 96$ & $70 \cdot 80$ & $64 \cdot 37$ \\
\hline PCU (million/day) & 3.68 & 3.62 & $3 \cdot 01$ & $2 \cdot 93$ & $2 \cdot 47$ \\
\hline Speed of Car in peak & $24 \cdot 00$ & $24 \cdot 29$ & 29 & $29 \cdot 27$ & $30 \cdot 93$ \\
\hline Speed of Bus peak period $(\mathrm{km} / \mathrm{h})$ & $21 \cdot 37$ & $21 \cdot 66$ & $25 \cdot 75$ & 25.97 & 27.52 \\
\hline Other external costs (Million Rs/day) & $72 \cdot 04$ & $70 \cdot 40$ & $58 \cdot 30$ & $56 \cdot 52$ & $46 \cdot 19$ \\
\hline
\end{tabular}


Table 4. Taxes in reference situation and optimal pricing (Rs/pkm, Delhi, 2005).

\begin{tabular}{lcrrrr}
\hline & RF & \multicolumn{1}{c}{ SP } & SO & PO & FO \\
\hline Peak car (small,petrol) & 1.57 & 1.57 & 4.48 & 5.04 & 11.17 \\
Off-peak car (small,petrol) & 1.36 & 1.36 & 1.68 & 2.61 & 13.53 \\
Peak bus & 0.03 & -0.07 & -0.07 & 0.03 & 3.55 \\
Off-peak bus & 0.04 & -0.16 & -0.16 & 0.04 & 2.09 \\
\hline
\end{tabular}

be socially and politically feasible to implement such a pricing policy because the public transport prices are either to remain constant or subsidized; and/or an extra tax cannot be imposed on private transport. Therefore, subsidy-based pricing (SP) or subsidizing public transport with optimizing private transport prices only (SO) or optimizing private transport prices only keeping prices of public transport at the reference level (PO) may be considered for effective reduction in congestion and modal shift in favour of public transport demand. It can be seen from the above tables that introduction of subsidy-based pricing (SP) leads to a decrease in social welfare by $0.30 \%$ indicating that subsidy-based pricing (SP) is not an ideal scenario from society's point of view. Introduction of 'subsidized optimum' (SO) or 'partial optimum' (PO) leads to a welfare gain of $0.34 \%$ or $0.84 \%$ respectively of generalized income, as compared to the reference situation, implying that if the policymaker cannot have perfect instruments to optimize both the public and private transport prices, then it can achieve a significant welfare increase and modal shift if it introduces optimal private transport pricing with and/or subsidized public transport prices ( $\mathrm{SO}$ or $\mathrm{PO}$ ) provided private transport is charged optimally. With SO, external costs of air pollution, noise and accidents decrease by Rs 13.74 million per day, a decrease of $19 \%$. The change in congestion condition is reflected in the overall decrease of passenger car units (PCU) by $20 \%$ and increase in peak period speed of car and bus by $21 \%$ and $20.50 \%$ respectively, though off-peak speed does not change very significantly $(6 \%)$ because congestion is not so problematic in the off-peak hours in the reference situation. The share of peak traffic decreased from $55 \%$ in reference situation to $52.52 \%$ in the full optimum situation, a drop of $4.5 \%$ in peak traffic. Besides, there is an important modal shift from private transport to public transport. Aggregated over peak and off-peak, the share of public transport rises from $59.89 \%$ in reference situation to $71 \%$ in the subsidized scenario, which is significantly higher than the modal shift of full optimum $(64 \cdot 3 \%)$.

3.4b Optimal tax levels: Table 4 gives information on the optimal tax (and subsidy) levels and compares them to the reference taxes. It may be pointed out that the taxes and subsidies are the instruments used to bring about optimal changes in traffic demand. Further, new taxes or subsidies would substitute all existing taxes in transport (fuel, registration taxes, and so on).

As can be seen from table 4, if the government has to subsidize pricing of public transport while optimally pricing private transport, then taxes increase for private transport in all periods, but to a higher extent for peak passenger car traffic for all car sizes. However, the tax increase in the SO scenario is much less than that of the full optimum scenario where the government has the policy instruments to levy optimal pricing for both private and public transport modes. In such a scenario it may be socially and politically acceptable for increasing the tax amount on private transport while subsidizing public transport. The modal shift is much more effective in the SO scenario than in the FO scenario. 
Table 5. generalized prices for reference and optimal pricing (Rs./pkm, per cent change w.r.t. reference, Delhi, 2005).

\begin{tabular}{|c|c|c|c|c|c|c|c|c|c|}
\hline & $\mathrm{RF}$ & SP & SO & PO & FO & $\begin{array}{c}\text { \% Change } \\
\text { in SP } \\
\text { over RF }\end{array}$ & $\begin{array}{l}\% \text { Change } \\
\text { in SO } \\
\text { over RF }\end{array}$ & $\begin{array}{l}\% \text { Change } \\
\text { in PO } \\
\text { over RF }\end{array}$ & $\begin{array}{c}\text { \% Change } \\
\text { in FO } \\
\text { over RF }\end{array}$ \\
\hline $\begin{array}{l}\text { Peak car } \\
\text { (small,petrol) }\end{array}$ & $8 \cdot 70$ & 8.67 & $11 \cdot 22$ & 11.77 & 17.79 & & 28.97 & $35 \cdot 20$ & $104 \cdot 48$ \\
\hline $\begin{array}{l}\text { Off-peak car } \\
\text { (small,petrol) }\end{array}$ & $7 \cdot 15$ & $7 \cdot 14$ & 7.45 & 8.37 & $19 \cdot 25$ & $-0 \cdot 14$ & $4 \cdot 20$ & $17 \cdot 18$ & 169.40 \\
\hline Peak bus & 2.08 & 1.97 & 1.78 & 1.88 & $5 \cdot 52$ & $-5 \cdot 29$ & -14.42 & -9.79 & 164.97 \\
\hline Off-peak bus & 1.95 & 1.70 & 1.67 & 1.89 & 3.98 & $-12 \cdot 82$ & $-14 \cdot 36$ & $-3 \cdot 13$ & $104 \cdot 41$ \\
\hline
\end{tabular}

Taxes are instruments of the optimal policy. The more relevant variable for the consumer is the generalized price of transport. Table 5 compares generalized prices in the reference situation to those of the optimal situation.

Table 5 shows that except in the subsidy-based pricing situation (SP), generalized prices of private transport mode are higher in optimal situations than the reference situation. Since welfare level under SP scenario is lower than that of the reference level we do not consider this 'counter-factual equilibrium' as the ideal scenario. Our main counter-factual equilibria are $\mathrm{SO}$ and FO and we compare the generalized prices under these scenarios with the reference situation. Whereas the tax increase (table 4) is quite substantial, the increase in generalized prices is more moderate. The reason for moderate tax increase is that tax increases, which cause money price increases, are partly offset by gains in travel speeds which lead to lower time costs. The net generalized price increase during peak hours for private transport is, due to internalization of external costs, approximately $54 \%$.

In the case of public transport, when the reference price level is subsidized, the generalized prices decrease in both periods. This is due to the decreasing money price and also decreasing time costs owing to firstly, increased speed and secondly, due to the Mohring effect; viz when public transport demand increases, the model assumes that the frequency of public transport services increases optimally leading to decreasing waiting time at public transport stops. This effect is partly responsible for the decrease in generalized price of public transport.

Table 6 gives additional information on the changes in price structure between the reference situation and the three pricing scenarios ( $\mathrm{SO}, \mathrm{PO}$ and $\mathrm{FO}$ ).

Table 6. generalized price components in reference and optimal pricing (small petrol car driven alone, Delhi 2005, Rs/pkm).

\begin{tabular}{|c|c|c|c|c|c|c|c|c|}
\hline & \multicolumn{4}{|c|}{ Peak } & \multicolumn{4}{|c|}{ Off-Peak } \\
\hline & $\mathrm{RF}$ & SO & $\mathrm{PO}$ & FO & $\mathrm{RF}$ & SO & $\mathrm{PO}$ & FO \\
\hline generalized price $(\mathrm{TC}+\mathrm{MP})$ & $8 \cdot 70$ & $11 \cdot 22$ & $11 \cdot 77$ & $17 \cdot 79$ & $7 \cdot 15$ & $7 \cdot 45$ & $8 \cdot 37$ & $19 \cdot 25$ \\
\hline Time cost & $2 \cdot 29$ & 1.90 & 1.89 & 1.78 & $1 \cdot 13$ & $1 \cdot 11$ & $1 \cdot 10$ & 1.06 \\
\hline Money price $(T+R C)$ & $6 \cdot 41$ & $9 \cdot 32$ & $9 \cdot 88$ & $16 \cdot 01$ & $6 \cdot 02$ & $6 \cdot 34$ & $7 \cdot 27$ & $18 \cdot 19$ \\
\hline Tax & 1.57 & 4.48 & 5.04 & $11 \cdot 17$ & $1 \cdot 36$ & 1.68 & $2 \cdot 61$ & 13.53 \\
\hline Resource cost & $4 \cdot 84$ & $4 \cdot 84$ & $4 \cdot 84$ & $4 \cdot 84$ & 4.66 & 4.66 & $4 \cdot 66$ & 4.66 \\
\hline Marginal external costs & $7 \cdot 00$ & $5 \cdot 64$ & 5.54 & 4.07 & $2 \cdot 39$ & $2 \cdot 24$ & $2 \cdot 38$ & $2 \cdot 28$ \\
\hline
\end{tabular}


The time cost component of the generalized price is found to decrease strongly in peak hours. This is the result of both increase in the money price (tax increase) and the decrease in time cost levels. For money prices and taxes, the opposite direction of effects holds. Since external costs are internalized in the generalized price, the share of the resource costs in the generalized price becomes smaller.

Under full optimum pricing policy taxes exceed marginal external costs. This relates to the efficiency of the global taxation system. Under subsidized optimum pricing policy taxes are about $80 \%$ of the marginal external costs, which is better than the reference scenario $(22 \%)$.

\section{Conclusion}

In this study we have developed a partial equilibrium model that captures transport tax reforms in the presence of certain transport externalities, namely, air pollution, congestion, noise and accidents in a single trip-purpose passenger transport market. The numerical model of our paper for Delhi showed that the gap between marginal social costs and current prices is quite large and congestion is the dominant source of inefficiencies. From the analysis of results of five scenarios, the following conclusions can be made:

(i) The cross-price elasticity of public transport demand with respect to the price of private transport is significant $(0.63)$ in the off-peak period whereas the same in the peak period is somewhat low $(0 \cdot 16)$ and the combined effect of these elasticities will result in a considerable modal shift in favour of bus transport demand (19\%) if the price of public transport is subsidized and private transport is priced optimally. Even without subsidy, the modal shift will be significant (18\%), if the under-priced private transport modes are optimally priced keeping the current bus prices constant.

(ii) There would be substantial welfare gains in both these scenarios. Since the own-price elasticities of public transport demand is small $(-0 \cdot 18)$ in the peak period and moderate $(-0.66)$ in the off-peak period, their combined efforts will not produce any undesirable effect, namely, their extra use of public transport costs more than what they are willing to pay.

(iii) Pricing instruments that do not tackle the congestion externality are much less efficient than policies that do: the full optimum pricing (FO) is better than partial optimum (PO) which is still better than the scenario where public transport is subsidized with optimally priced private transport (SO). The results show that the current tax for driving one kilometer by small car in the peak period is Rs 1.57 whereas the efficient tax should be Rs 11.17 under full optimum pricing. Since full optimum pricing policy, which requires very steep increases in both private and public transport prices $(611 \%$ \& $80 \%$ respectively), may not be feasible due to social and political reasons, implementation of subsidized optimum (SO) or partial optimum (PO) pricing policies which require efficient tax rates of Rs 4.48 and Rs 5.04 respectively for driving the same distance by the same mode and period may be feasible in the short run.

(iv) For the Delhi case, the reduction in external costs is achieved by a reduction in both peak and off-peak period passenger car and bus travel. The overall traffic level decreases by nearly $30 \%$, the share of peak travel decreases (from $55 \%$ in reference situation to $52.52 \%$ in SO and further to $50.28 \%$ in full optimum) and the share of public transport, aggregated over peak and off-peak period, increases (from 59.89\% in reference situation to $71 \%$ in subsidized optimum and $70.80 \%$ in partial optimum situation compared to $64.3 \%$ in full optimum), indicating a significant modal shift in favour of public transport. 
(v) The combination of a decreased peak traffic volume and a switch to the public transport mode leads to increased travel speed. In the optimal policy scenario, peak period speed of car increases by $28.6 \%$ (from $24 \mathrm{~km} / \mathrm{h}$ in reference situation to $31 \mathrm{~km} / \mathrm{h}$ in full optimum) whereas it increases for public transport by $31 \%$ (from $21 \mathrm{~km} / \mathrm{h}$ in reference situation to $27 \mathrm{~km} / \mathrm{h}$ in full optimum). Under subsidized pricing, the change in congestion condition is reflected in the overall decrease of passenger car units (PCU) by $20 \%$ and increase in peak period speed of car and bus by $21 \%$ and $20.50 \%$ respectively.

If reduction of congestion and other transport externalities is the prime motive of the policymaker, then there is a case for subsiding public transport. Either subsidizing bus prices or keeping the current bus prices unchanged but optimally pricing the private transport modes would induce people to switch from private to public transport mode. In the first case, the loss in tax revenue due to subsidized pricing of public transport is compensated by the gain in tax revenue from the optimal pricing of private transport. Apart from pricing measures, the success of modal shift also depends on the quality parameters of bus services, which will increase the value of the own- and cross-price elasticities thereby influencing a more significant modal shift.

\section{References}

Anas A 1982 Residential location markets and urban transportation: Economic theory, econometrics, and policy analysis with discrete choice models. (New York: Academic Press)

Anas A 1985 The combined equilibrium of travel networks and residential location markets. Regional Science and Urban Economics 15: 1-21

De Borger B, Mayeres I, Proost S, Wouters S 1996 Optimal pricing of urban passenger transport-a simulation exercise for Belgium. Journal of Transport Economics \& Policy 31-54

De Borger B, Proost S 2001 Reforming Transport Pricing in the European Union-A Modelling Approach (Cheltenham, UK: Edward Elgar Publishers)

Glaister S, Lewis D 1978 An integrated fares policy for transport in London. Journal of Publ. Econ. 9: $341-355$

I-CE 2000 The economic significance of cycling (The Hague: VNG uitgeverji)

Keller W J 1976 A Nested CES-type utility function and its demand and price-index functions European Econ. Rev. 7: 175-186

Kraus M 1989 The welfare gains from pricing road congestion using automatic vehicle identification and on-vehicle meters. Journal of Urban Economics. 25: 261-281

Kraus M 1991 Discomfort externalities and marginal cost transit fares. J. Urban Econ. 29: 249-259

Ochelen S, Proost S 1996 Internalization of transport externalities by a local government. Paper presented at NBER Workshop on Public Policy and the Environment, Cambridge

Ochelen S, Proost S, Van Dender K 1998 Optimal pricing for urban road transport externalities. CES Discussion Paper Series, 98.26, (Leuven, Netherlands: Department Economic, Katholieke Universitiet Leuven)

ORG 1994 Household travel survey in Delhi. Final Report (New Delhi: Operations Research Group)

Pigou A C 1920 The Economics of Welfare (London: Macmillan)

Proost S, Van Dender K 2001 The welfare impacts of alternative policies to address atmospheric pollution in urban road transport, Regional Sci. \& Urban Econ. 31(4): 383-412

Registrar General and Census Commissioner of India 2001. Provisional populations totals. Paper 1 of 2001 (New Delhi: Office of the Registrar General, India)

RITES 2005 Integrated multimodal public transport network for NCTD—Final Report (New Delhi: Transport Department, Government of NCT Delhi)

Small K 1983 The incidence of congestion tolls on urban highways. J. Urban Econ. 13: 30-111 